\title{
"You Are First a Chinese Citizen, Then A Consumer": Presenting and Balancing Identities Online as Chinese International Tourists
}

\author{
Fangheyue Ma \\ Florida Gulf Coast University, USA
}

DOI: https://doi.org/10.18778/1733-8077.17.4.04

Keywords:

China; International

Tourism;

Consumption; Social Media; Presentation of Self

\begin{abstract}
This paper is based on the analysis of 261 video and word posts collected from four popular social media sites on which Chinese tourists shared their consumption-related experiences during and after the trip. It investigates Chinese international tourists' diverse presentations of self to a broad audience online through explaining their shopping experiences and product reviews. Tourists are expected to balance multiple identities carefully when they project themselves online as consumers-on the one hand, they present themselves as global consumers and trendsetters who are strategic and savvy; while on the other hand, they still need to preserve and even emphasize their national identity as Chinese patriots. Providing the much-lacking qualitative insight, this study enhances our understanding of international tourists and their consumption behaviors, the construction and presentation of a digital self, and how globalization operates at the micro-level.
\end{abstract}

Fangheyue Ma is an instructor at Florida Gulf Coast University, Department of Sociology. She has a Ph.D. from the Department of Sociology at the University of South Florida. Fangheyue's research and teaching interests include cultural sociology, specifically the cultural phenomenon of international tourism, social psychology, particularly the subfields of identity, interaction, and emotion. Her current research focuses on Chinese international package tours in the US, centering on Chinese tourists' collective presentation of themselves as tourists and Chinese nationals, their emotional experiences, interactional rituals, and the construction of meanings during the trip. Her work aims to provide a micro-level understanding and reflection of the macro-level topic of globalization and the global economy.

email address: fma@fgcu.edu 


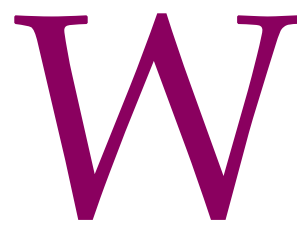

ith a population of 1.4 billion, China generates the greatest number of international tourists worldwide. According to The Outbound Chinese Tourism and Consumption Trends: 2017 Survey ${ }^{1}$ jointly issued by Nielsen and Alipay, Chinese tourists traveled overseas on 131 million occasions in 2017, with an increase of 7 percent from the previous year. Among all the destinations visited, nearly three million Chinese tourists visit the US annually, spending over $\$ 30$ billion per year. While shopping may not be the primary motivation for most travelers, it is a universal tourist activity that often adds to the overall attractiveness of almost every region in the world (Jansen-Verbeke 1987; Butler 1991; Prus and Dawson 1991; Page 1992; Law 1993; McIntosh, Goeldner, and Ritchie 1995; Chen 1997; Kincade and Woodard 2001; Reisinger and Turner 2002). Even though China is an active participant in the global marketplace, shopping while traveling abroad is still a prominent trend among Chinese tourists despite most brands examined in this paper being available in China.

In addition to the existing close link between shopping and tourism, the widespread use of social media applications adds another layer for the scholarly exploration of tourism, consumption, and the presentation of self. Currently, tourists not only post their travel experiences on different social media platforms but also share their shopping experiences, recommend what to buy to others, and review the products they purchased during and after their trips. Their roles as tourists and consumers are much expanded when they decide to post their shopping experiences online. With the help of social media, tourists are capable of presenting themselves as cul-

\footnotetext{
1 See: https://www.nielsen.com/wp-content/uploads/sites/3/2019/05/ outbound-chinese-tourism-and-consumption-trends.pdf. Retrieved July 30, 2017.
}

tural intermediaries, trendsetters, and global consumers. Further, shopping is also used to promote their national identity as Chinese patriots and loyal citizens. In the social media age, the timely issue of how people's identities are constructed and shaped by the interactions online is worth exploring.

Nowadays, tourists can construct and present diverse digital selves in virtual settings. In physical spaces, there is a limited audience and time for every performance; but, for interactions online, people's audiences can theoretically keep expanding indefinitely, and the performance never has to end. At the same time, it is worth noting that such tourists' presentations of self are monitored and policed in stricter ways by their much-expanded pool of virtual audiences, compared to traditional faceto-face interactions in physical settings. In other words, successful presentations of self in virtual settings require performers to acquire approvals from a much-expanded group of audiences outside their intimate life circles. Consequently, Chinese international tourists sometimes need to balance multiple different, even competing, identities while doing self-presentations online.

Being a part of a larger study on Chinese international tourists in the US, this present paper aims to better understand how Chinese international tourists present themselves in virtual settings through the discussion of their shopping experiences. To answer this research question, data from four social media platforms were examined: travel journals from one open-access travel forum (www.mafengwo.cn), short and long videos about shopping experiences, and product reviews that are posted on social media platforms like Red, Weibo, and Bilibili. This study contributes to the field of tourism studies and the investigation of identity construction in the social media age in multiple ways-on the one 
hand, it provides the much-lacking qualitative insights in the exploration of tourists' consumption behaviors when they travel internationally; while on the other hand, it extends Goffman's theoretical framework by looking at self-presentation and identity construction in virtual settings.

In the following section, a literature review is undertaken to discuss Goffman's theoretical framework of the presentation of self and the connection between consumption, tourism, and identity. Following this, methodology and data collection across different platforms are discussed. In the following section, through describing their consumption practices, sharing what they bought during the trip, and offering product reviews, Chinese tourists present themselves online as 1) good community members; 2) smart and competent global consumers; 3) trendsetters and cultural intermediaries; 4) good Chinese patriots. Simultaneously, many are expected to strategically balance their global and national identities toward their audiences in mainland China so that their followers do not feel offended or betrayed. Finally, I conclude and set out future avenues of research.

\section{Theoretical Framework and Literature Review}

\section{Goffman's Theoretical Framework: The Presentation of Self}

In his work, The Presentation of Self in Everyday Life, Goffman (1959) explored the presentation and management of the self during social interactions with considerable insight. Utilizing the metaphor of social life being a "theater" and people being "performers," Goffman described in great detail the back versus front stage operations and the presentation of self in social encounters. According to Goffman, performers achieve their ideal identities in different interactional arenas through performances. At the same time, the competent performances are under social constraints and subject to the disposition of relevant audiences in social interactions (Gecas 1982). This means that they need to deliver different performances when facing different audiences. Thus, based on Goffman's work, identities are constructed both by actors through performances and by others who serve as audiences in different situations.

Goffman claims that to understand identity, researchers could look into the intentional and tangible component of self-self-presentations. Through the dramaturgical lens, people are social actors that engage in different presentations of self to manipulate other people's impressions of them during social interactions. In this way, the presentation of self is achieved through the corporeal display in communicating the desired or potential self across different social settings (Belk 1988). However, with the voluntary usage of social media, users' imaging can transform into publicly accessible artifacts (Patterson 2018). With the worldwide prevalence of the Internet, smartphones, and social media applications, researchers have started to conduct studies exploring people's presentation of self in online and virtual spaces without having to engage in any corporeal interaction (Kendall 1998; Zhao 2005; Gottschalk 2010; Ictech 2019). The idea of self-presentation serves as the theoretical framework for the analysis of Chinese tourists' presentation of self and balancing of multiple competing identities online through sharing their shopping experiences and product reviews.

\section{Identity, Consumption, and Tourism}

The discussion of self and identity in the field of sociology asks the question of "who am I?" From 
the symbolic interactionist perspective, one's self and identity, although sound intimate, and internal, are unavoidably constructed through identification with others. As Charles Horton Cooley (1983) suggests when he discusses the concept of the "looking-glass self," the self operates in the imagination, drawing from, reflecting upon, and responding to real and imagined others. Building on Cooley's work, Mead (1934) suggests that one's self is born out of reflexive actions from interactions, and the base of the self is an awareness of the generalized other. In today's society, our self and identity can be conceptualized as a social product created and sustained during interactions in the social world (Kroger 1989; Côté 2006).

The relationship between consumption and identity is emphasized in Consumer Culture Theory (CCT) that deals with the "sociocultural, experiential, symbolic, and ideological aspects of consumption" (Arnould and Thompson 2005:868). Being one of the most central human practices, consumer culture and its dual activities have greatly contributed to the construction of people's identities. According to Bourdieu (1984), consumption is not only an economic but also a symbolic activity people adapt to separate themselves from others. Through the process of purchasing goods that they do not need, consumers construct some of their identities from the possession of new products (Stearns 2006). Material possessions, on some level, become the extension of the self, and the display of material goods helps affirm their owners' identity (Belk 1988). Therefore, it is through the consumption experiences that modern individuals build their identity, as well as assure its coherence (Parmentier and Rolland 2009).

While tourism has existed as a mass phenomenon at least since the late nineteenth century, the expan- sion of road transport infrastructure and a decrease in the cost of air travel have encouraged the industry's expansion. As a result, the rise of domestic and international tourism has transformed consumption both in form and in content. Warde (2015) discussed how consumption could help promote social interaction, friendship and kinship, elite formation, the gift economy, collective mobilization, social solidarity, and rebellion (McCracken 1990; Thornton 1995; Maffesoli 1996; Noble 2004; Reimer and Leslie 2004; Martens and Casey 2016). Moreover, scholars have studied international tourists' souvenir and general shopping behaviors, preferences, and expenditures in the age of globalization (Lehto et al. 2004; Albayrak, Caber, and Çömen 2016; Jin, Moscardo, and Murphy 2017; Sthapit 2017).

As for the investigation of Chinese tourists' consumption behavior, there is a dominant trend that focuses on tourists' shopping motives (Chan et al. 2014; Tsang, Lee, and Liu 2014; Correia, Kozak, and Kim 2018) for both daily necessities and luxury products when they travel internationally. Several previous studies have also focused on tourist shopping satisfaction at the destination level (Lin and Lin 2006; Liu, Choi, and Lee 2008; Wong and Wan 2013). Apart from that, another line of research has provided the profiling information regarding Chinese international tourists as consumers (Huang and Lu 2017; McKercher et al. 2020) that includes the youthful "second-wave" (Arlt 2013; Cheng and Foley 2018), as well as the elite middle-aged Chinese outbound travelers with ample buying power (Bao, Jin, and Weaver 2019; Liu and Li 2020). One clear gap within the existing literature is the lack of qualitative exploration. The majority of the previous research mentioned in this section used quantitative survey methods and statistical analysis. Therefore, this area of research calls for more qualitative stud- 
ies that provide thick descriptions and micro-level complex explorations for Chinese tourists' consumption behaviors.

\section{Globalized Consumer Identity as Cultural Intermediaries}

Previous studies have discussed the blurred boundaries between mass media and physical consumer products by looking into the phenomenon of consumers becoming cultural intermediaries (Lash and Lury 2007). The concept of a "cultural intermediary" addresses how individuals who tend to be early adopters of new fashions or lifestyles gradually become professional intermediaries between brands and consumers and have a significant influence on a broad swath of the population (Bourdieu 1984; Featherstone 1991). These individuals adopt the ethics of self-expression through consumption and promote new products and lifestyles in everyday and relatable ways (Sassatelli 2007; Maguire and Matthews 2012). On a similar note, Schor (2004) looked at the phenomena of "stealth marketing," discussing how large brands and corporations use various means to smuggle a marketing message so that it is seamless.

Web 2.0 and modern social media applications now provide people with multiple platforms to mediate between manufacturers and consumers. This phenomenon offers a distinct twist on traditional understandings of what consumption looks like. Traditionally, companies that produce products and services directly advertise them for consumers to buy. However, with various social media platforms, users sometimes unwittingly provide free advertising for products and services they like by sharing a review on YouTube or Facebook (Rojek 2011). These new media platforms have a democratizing effect on the production and distribution of media content by undercutting the monopoly previously held by media companies and advertisers (Strangelove 2010). Large companies have started to encourage consumers to share testimonials regarding the products that speak positively and sincerely about the brand and use these narratives in their marketing as a source of profit for their brand (Foster 2011). As a result, it requires researchers to study consumption through a different lens and further cultivate social media as a critical source of data.

\section{Consumer Citizenship and the Nation-State}

In the age of globalization, many consumers not only see consumption as a means of personal satisfaction but also as a tool of political expression. In many ways, consumers act as citizens through actions in both domestic and international marketplaces. In turn, during certain historical moments, such as in the context of a trade war, government officials encourage citizens to consume, exchange, and dispose of specific types of products to help the nation achieve its political and economic goals.

Many previous works across different disciplines have explored the relationship between nationalism, tourism, and consumption behavior (Pretes 2003; Baillargeon and Gélinas 2011). Cohen (2003:204) made a distinction between citizen-consumers and consumer-consumers and defined the former as "consumers who take on the political responsibility we usually associate with citizens to consider the general good of the nation through their consumption," while consumer-consumers are those who seek primarily to "maximize their economic interests in the marketplace." Overall, consumers who act as citizens began to organize to achieve collective goals through co-operatives and boycotts beginning 
in the eighteenth century and continue to do so to the present day. This connection between consumer citizenship and nation-state illustrates that in some settings, consumers can express and enact the values and goals of solidarity and social change, construct and present their collective national identities through consumption. Consumer politics has taken many forms, from consumer associations concerned with product quality to campaigns to "boycott ${ }^{2}$ " large brands to pressure companies to change specific policies and improve working conditions and fair trade (Gabriel and Lang 1995; Daunton and Hilton 2001). Other work has also been conducted to understand related concepts such as consumer ethnocentrism (Pecotich and Rosenthal 2001) and animosity (Shimp and Sharma 1987) that aim to understand the appropriateness and morality of purchasing foreign brands.

In addition to this, many existing works have focused on Chinese nationalism and its connection to consumer behaviors. Because of the strong anti-foreign feeling together with a victim complex (Wu 2006), many Chinese nationalists tend to frame and rationalize their behavior based on past humiliations (Gao 2012) and collective memories of past national experiences (Carlson 2009). As for the impact of grassroots nationalism in China on foreign brands, Gao (2012) has identified four fronts, including the political, cultural, economic, and consumer rights. A few scholars from various disciplines have also looked at Chinese consumers' resistance to foreign brands (Hooper 2000; Wang 2006; Li 2008; Lu and Weber 2009), while some empirical work has examined the influence of nationalism on Chinese tourists regarding the Diaoyu/Senkaku Island Inci-

\footnotetext{
${ }^{2}$ Deliberately purchasing a company's or a country's products in support of their policies, or to counter a boycott.
}

dent between China and Japan since late 2012 ( $\mathrm{Li}$ 2009; Cheng and Wong 2014).

Historically less powerful groups have used the space of consumer citizenship to claim collective rights and demand equality not only in the economic but also in the political sphere. Nelson's (2000) study of consumer nationalism in South Korea looked at how South Korean activists and government officials discouraged their citizens from consumption to promote a distinct road to economic development. In China, while modern consumption developed alongside the rise of the nation-state, government officials, businesspeople, and activists sought to persuade Chinese individuals to only purchase Chinese-made goods to further advance Chinese nationalism (Gerth 2008). In contrast to the Western model of mass consumption without the involvement of the nation-state (Ritzer 2003; Smart 2010), these cases demonstrate the vital role of the nation to understand specific patterns of consumer citizenship.

In summary, literature on tourism, consumption, and identity construction has focused on how consumption is used in multiple ways to help consumers present themselves and construct different identities towards distinct groups of audiences. In many cases, consumers can even become cultural intermediaries between brands and their potential consumers. Sometimes, consumers can use their consumption power to preserve and emphasize their national identities. However, existing literature overlooked the issue that examines how social media and the act of "posting experiences online" further shape people's self-presentation. This requires an extension of Goffman's theory to not only look at the presentation of self during corporeal but also virtual interactions. As a considerable amount 
of our self-presentation and identity construction relies on interactions happening in virtual settings nowadays, the role of social media and how it shapes our self-presentation is still not being sufficiently explored. In addition to that, empirical exploration of consumer citizenship mainly focused on how consumers chose to reject foreign brands and purchase products made in their country. In the case of international tourism, the phenomenon that tourists manage to maintain their national identities while purchasing foreign brands is understudied.

\section{Data and Methods}

In this paper, social media is an essential field in understanding how tourists, both as consumers and social media users, talk about their consumption experiences while at the same time construct their identities in virtual settings. The data sets assembled in this paper were collected from four social media platforms that are the most popular among Chinese tourists: Mafengwo (www.mafengwo.cn), a Chinese social media site for travelers to share tips, pictures, and travel logs about their worldwide traveling experience; Red, a social media and e-commerce platform that allows users to share product reviews, travel blogs, and lifestyle stories via short videos and photos; Weibo, a Chinese microblogging website similar to Twitter that allows word-, picture-, and video-postings; and Bilibili, a popular video-sharing social media platform that many Chinese tourists use to post longer travel video logs or "vlogs" and "haul" videos. ${ }^{3}$

Given that all four social media platforms have hundreds of millions of Chinese users worldwide, the focus was narrowed down by limiting the sample

\footnotetext{
${ }^{3}$ A video recording, posted on the Internet, in which a person discusses their fashion and beauty purchases (Romano 2010).
}

to posts from January 01, 2014, to December 31, 2018, made by Chinese tourists who have visited the US. In addition to that, the results on all sites were filtered by popularity to capture the most popular posts that reached the greatest number of users. I have also excluded posts that only offered concrete travel tips and did not have individuals' travel and consumption experiences. This research went through an in-depth analysis of 261 posts, which included travel logs, short product-review videos, as well as longer travel vlogs, and shopping haul videos. The sampling process was concluded when similar information began to emerge, which indicated that the data had reached a saturation point.

These four social media sites were chosen not only because they are popular among tourists who want to share their experiences but also because they contain a rather comprehensive format of qualitative data that includes words, pictures, and videos. Therefore, the data incorporate an exploration of the more diverse forms of digital data that are available nowadays.

Mafengwo is a Chinese travel forum founded in 2006. Currently, it has over 300 million users worldwide, and it covers over 95 percent of the popular travel destinations in the world. Tourists can post their travel logs, pictures from their tour and share travel tips about hotels, flights, local culture, along with their recommendations of local restaurants and places to shop. On Mafengwo, many tourists share their shopping-related experiences in various outlets, department stores, and luxury shops. Some share and briefly review the products they bought during the trip to provide insights for future travelers. This research selected 55 posts from Mafengwo, most of which are 1500 to 2000 words long with 10 to 30 pictures each. 
Red is a social media site founded in 2013 with a current worldwide user base of over 500 million. The majority of its users are Chinese people around the world. This particular social media application does not have a web version, and all posts are documented through smartphones. On Red, people can either share product reviews, travel experiences, and lifestyle tips via videos shorter than 60 seconds or post pictures or screenshots of various note-taking apps if they wish to share more words. To collect data, I analyzed 156 short videos and photo posts on Red.

The third site chosen for this paper is Weibo. Weibo is a Chinese microblogging website and one of the biggest social media platforms in China. By searching keywords and hashtags such as \#USshoppinghaul and \#whatIboughtintheUS, I chose to analyze 30 shopping-related videos posted on Weibo between the selected period.

The fourth and final site is Bilibili, a Chinese video-sharing website equivalent to YouTube. On Bilibili, Chinese tourists can share longer posts about their trip in video format. In total, 20 longer videos were analyzed on Bilibili. The content of video posts both on Weibo and Bilibili include shopping videos that feature the live footage of the tourists visiting different department stores and outlets, as well as videos where tourists shared what they had purchased with their online audiences.

To analyze the data, an inductive approach was taken (see: Glaser and Strauss 1967). As the study proceeded, relevant categories emerged from the data. In particular, grounded theory was used to analyze the online posts. According to Charmaz (2014), researchers' active involvement in coding is a crucial part of the grounded theory process, and the data collection and analysis should be conducted sequentially with preliminary data analysis informing future data collection. For the online posts collected for this study, I wrote theoretical notes to creatively analyze the data and link the emerging categories to the existing literature. Gradually, I integrated the theoretical notes into analytical memos that helped further focus the study. The data analysis process continued during and after data collection until I developed guiding theories, a general scheme, and identified an overall pattern and categories for data analysis. All of the collected data were in their original language, including simplified Chinese and Mandarin. As a native Mandarin speaker, I translated the data from Chinese to English for the purposes of this paper. Meaning-loss was inevitable; however, I mitigated against this to preserve the meanings contained in its original language by providing context and necessary annotation.

In addition to the use of memos, the ongoing process of coding these online posts was central to the data analysis. Accomplishing this goal required reading and rereading the data to highlight and label important, descriptive, and informative issues that emerged for later sorting and categorization. I examined the data to identify and discover classes of things, persons, and events, as well as the properties that characterized them. The ultimate goal for the grounded theory approach was to develop theories that account for Chinese tourists/consumers' meaning-making processes and their presentation of self when they talk about their shopping experiences. Data collection ceased when no new ideas or concepts emerged, and when no negative cases could be found that disconfirmed or invalidated the proposed framework of analysis for each data set. In the end, a total number of 261 cases from all data sets were analyzed. 


\section{Chinese International Tourists' Diverse Presentations of Self on Social Media}

Mainland Chinese and Taiwanese tourists spend 61 percent of their money on shopping while US residents, Canadians, Europeans, and Australians spend from 28 to 37 percent of their money on shopping activities (Heung and Qu 1998). Based on the data analyzed, shopping is one of the primary motivations of outbound tourists traveling from China. In the travel logs posted on Mafengwo, Chinese tourists offer various tips about bus schedules to outlet malls, acquiring coupons in stores, and paying attention to different holiday sales in the US; while in both short and long haul videos posted on Red, Weibo, and Bilibili, tourists often mentioned how important shopping is to them during their trip. Multiple people talked about purchasing a second or third suitcase to store the products they bought in the US, as well as staying in cheap hotels or hostels to save money for shopping. Shopping opportunities are everywhere, and as Underhill (1999:31) puts it, "you almost have to make an effort to avoid shopping today."

Furthermore, with the prevalence of social media and smartphones, people's presentations of self rely heavily on various digital platforms. Utilizing various forms of posts, including videos, pictures, and words, Chinese tourists who travel to the US can present themselves to their virtual audiences online. Different features of social media platforms, such as the use of hashtags and labels, greatly expand the pool of audiences their posts can reach while at the same time, the imagined feedback from the audiences will, in turn, further shape their self-presentations. In this section of the paper, I explore Chinese tourists' presentations of self virtually by sharing their shopping experiences on different social media platforms and thus form different digital identities.

\section{Chinese International Tourists as Good Community Members}

From approximate calculations based on the prices and discounts mentioned in the videos and travel logs, the Chinese tourists analyzed in this paper have estimated budgets from $\$ 1000$ to over $\$ 20,000$ during an average 15-day trip. Among various products they purchased during the trip, souvenirs and gifts constituted the smallest portion of their travel budgets. The purchase of souvenirs and gifts was perceived as an obligatory aspect of their trips, both for their memories of the trip and the maintenance of healthy relationships with friends, family members, and colleagues. For instance, one person, who purchased a necklace from a local souvenir shop at the Grand Canyon, stated that it was "the only souvenir I bought to remember this trip." Another tourist discussed purchasing a Hollywood keychain in Los Angeles near the Hollywood Walk of Fame. She noted that "one does not have to buy too many souvenirs because they are not practical. Purchasing only one or two things to remember the trip is enough."

Moreover, Chinese international tourists examined in this study purchased gifts for close ones not only from the souvenir shops but also from supermarkets like Walmart and Trader Joe's. One tourist spoke about purchasing large bags of chocolates, Tostitos chips, and nut boxes from Walmart as gifts for friends and colleagues. According to him, these types of products both "represent American culture and are more practical than a fridge magnet or a keychain because you can eat them." Posting online about their experiences of selecting souvenirs for various groups of people helps Chinese tourists construct their identity as good friends, colleagues, and thoughtful family members. This particular idea was discussed by one of the tourists in her short video posts: 
When you travel to the US, you cannot come back to work empty-handed. Even without bringing it up intentionally, your colleagues always expect you to bring them something from your travel destination. I bought these three large packs of chocolate from Walmart as gifts for people in my office. We can share them, and one pack only costs about five dollars.

As demonstrated by this post, when people travel internationally, an almost unspoken rule is that one cannot return empty-handed. Purchasing souvenirs that friends and family can share helps maintain healthy relationships without having to choose separate gifts for everyone. Another person mentioned purchasing a Harvard sweatshirt and baseball cap for her little brother as an "inspirational gift." According to this tourist, the most appropriate kind of gift for younger family members should be both practical and inspirational. Simultaneously, this helps maintain healthy relationships with relatives due to the goodwill this product creates. No matter if it is several packages of chocolates, one box of nuts, a sweatshirt, or a couple of keychains, most people discussed the obligations to buy gifts for people they are close to. Although not costing a large amount of money, gifts are always considered necessary. Discussing their experiences selecting souvenirs aids tourists in presenting themselves as thoughtful and considerate and thus construct healthy relationships with friends, relatives, and colleagues.

\section{Chinese International Tourists as Competent and Smart Global Consumers}

In addition to souvenirs and gifts, most of the tourists' posts also mentioned purchasing products such as clothing, sneakers, electronic products, and nutritious supplements from Western brands. Nearly all accounts analyzed discussed purchasing clothing, shoes, and various accessories from large retailers like H\&M, Gap, Forever 21, Levi's, American Eagle, et cetera, as well as sports brands such as Nike, Adidas, Converse, and Under Armor. While most of these Western brands are available in China with a price markup, the inaccessibility of items due to very high cost fuels the idea of tourists as shoppers. For instance, many shared their experiences purchasing different skincare and cosmetics products while traveling to the US. One tourist wrote in her travel log about doing " 80 percent of the shopping in Sephora ${ }^{4 \prime}$ and discussed purchasing numerous products to "stock up for the entire year because it's so much cheaper here." Besides that, many detailed their experiences purchasing luxury Western brands like Gucci, Louis Vuitton, and Hermes.

According to Keown (1989), relative prices are one of the most influential factors in generating shopping tourism. Together with the rapid growth in popularity of outlet malls and factory shops, tourists attest to the importance of good value and price. Given the enormous demand for shopping by tourists, many destinations have launched major shopping promotional campaigns and have adopted retail and tourist shopping as official policies in their tourism development efforts, thus further expanding the price advantages (Jansen-Verbeke 1990). Below is an example in which a Chinese tourist shared tips for purchasing luxury products during a trip:

If you want to buy luxury products in the US, Hawaii should be your first choice because their sales tax is only $4 \%$, and it is the lowest in the US. I purchased my Hermes handbag in Hawaii without having to first buy other of their products that match the price of the bag because they knew you are tourists, and you are not

\footnotetext{
$\overline{{ }^{4} \text { A multinational }}$ chain of personal care and beauty stores.
} 
able to stay there long to accumulate the credits. ${ }^{5}$ I only bought a $\$ 4,600$ bracelet and a $\$ 600$ pillow, and then the salesperson took me to see their handbag collection in the back. I ended up purchasing this beautiful $\$ 8,600$ Hermes bag in only one visit. Everyone should try their luck in places like Hawaii and Las Vegas.

\section{Figure 1. A Chinese tourist showcases her "haul"} after a shopping day at an outlet. At the bottom of the picture, she states, "Shopping for an entire day makes me feel so happy"

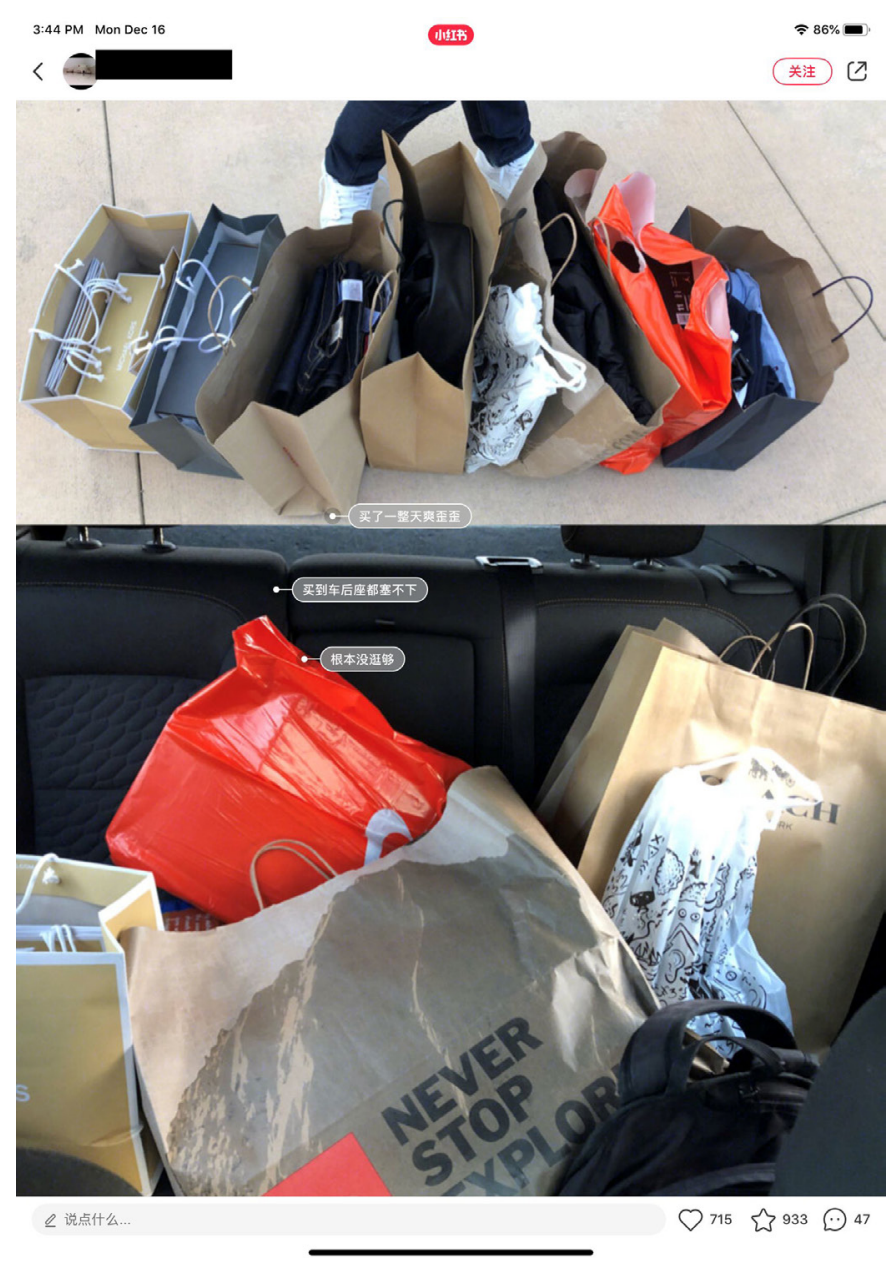

Source: Platform Red.

${ }^{5}$ One unspoken rule in many luxury shops is that consumers will first have to buy a certain number of "unpopular" products like shoes, clothing, belts to accumulate their credit and status for the most popular handbags.
As shown in these video posts, "being strategic while shopping" is a theme that frequently emerges when Chinese international tourists discuss their consumption experiences in the US on different social media platforms. Many tourists mentioned that the price for the same product is two to five times higher when purchased in China. Discussing their experiences and strategies for finding different deals both for everyday and luxury products while traveling to the US helped Chinese international tourists present themselves as well-off and smart global consumers. In the videos and travel logs that I analyzed, many cannot hide their excitement talking about the deals they discovered while traveling in the US. Most of them are noticeably proud of their ability to locate good deals, as, according to one tourist, "you are saving money while spending money." The following two examples each reveal how Chinese international tourists construct and manage their identities as savvy global consumers:

In China, one Tommy Hilfiger T-shirt will cost me about $\$ 100$, and I'm really not willing to spend so much money on a plain logo shirt. When I went to the outlet in the US, I was shocked by the low price of this brand-it's only $\$ 20$ !...I've had my eyes on this pair of Coach sneakers back in China for a long time, and I did not even dare to try it on in the store because I knew I could not afford it. It costs about $\$ 500$ in China and owning a pair of $\$ 500$-dollar sneakers is unimaginable for me. When I travel to the US, I went to the Coach outlet store and saw the exact same pair for $\$ 90$ ! That's why I went for it immediately. I love it so much!

You can buy Coach, Michael Kors, and Samsonite with your eyes closed! There's no need to compare the prices because it's definitely cheaper here in the US. The prices from these brands are almost half com- 
pared to the prices in China. If you buy it in outlets, they will have additional discounts.

\section{Figure 2. A Chinese tourist posted a long article} to offer an extensive guide to all the outlets near San Francisco

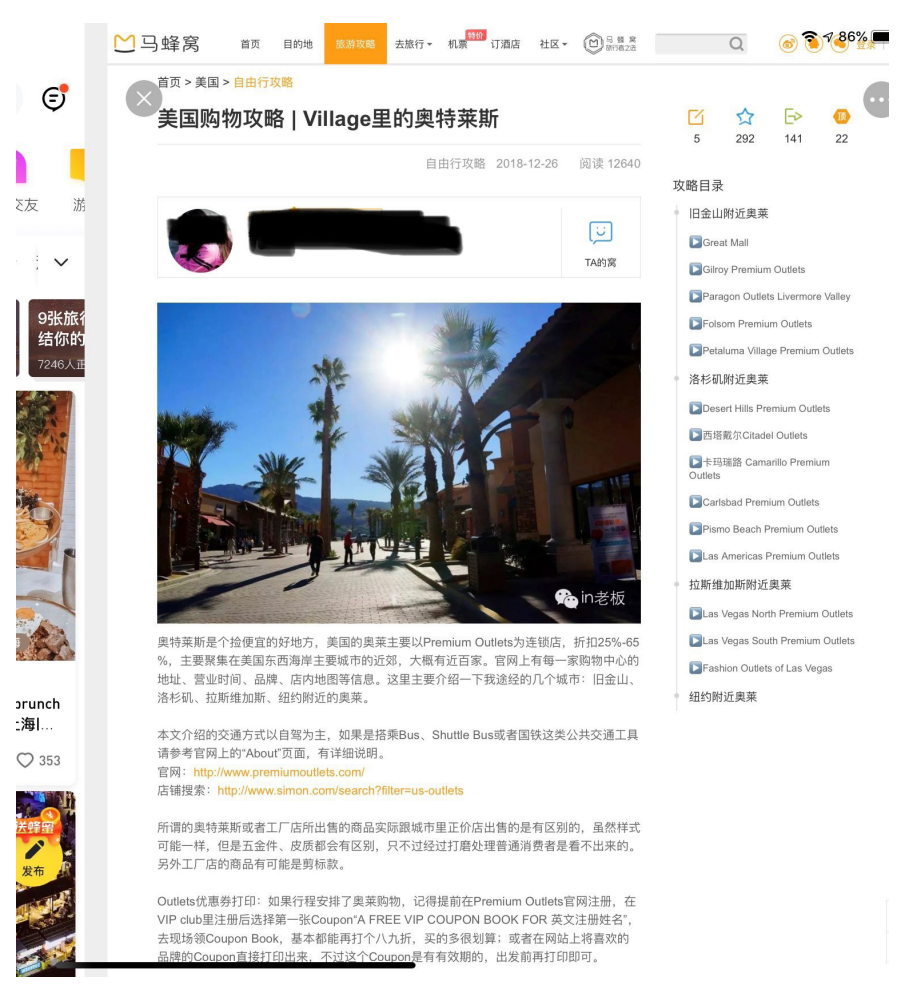

Source: Platform Mafengwo.

In the above examples, Chinese international tourists shared their experiences finding good deals on Western brands when they travel to the US and justified their consumption by reference to the large price differential for certain products between the two countries. There are many more examples from the data analyzed that saw significant price difference as the major shopping motivation while traveling in the US. At the same time, discussing shopping strategies helped them confirm their shopping skills publicly. One tourist even went as far as to create a Google Doc to track different deals during her trip. After sharing the document with her viewers on Bilibili, many people complimented her as the most "hardcore deal-catcher" on the Internet. Upon my latest visit to her page, I found that she has responded and further altered her online performance as her viewers affirm her identity as a strategic and savvy buyer. For example, she mentioned in one of her videos that many other bloggers were copying her act of tracking discounts using interactive files and that she had even set up a discount-tacking website on her own to make it easier for her audiences and separate herself from other bloggers. Overall, one consistent message that was apparent from these posts was that Chinese tourists are well-off and willing to spend a lot of money when they travel, but they remain savvy and strategic. They will evaluate deals and make shrewd decisions accordingly. Sharing shopping tips and justifying their consumption practices using the price differential helps Chinese tourists present themselves as competent and smart global consumers.

\section{Chinese International Tourists as Trendsetters and Cultural Intermediaries}

The prevalent use of social media and smartphones during and after trips adds another layer to the exploration of tourists' roles as consumers. Tourists post about their trips online not only to share their experiences with friends and family but also strangers who are seeking travel tips, things to buy, and general shopping information. Social media platforms enable them to reach a broader audience when sharing their perceptions and experiences. In this way, Chinese international tourists present themselves as trendsetters and cultural intermediaries between China and the US. 
When searching for questions, labels, and hashtags such as "what to buy in the US," "US shopping haul," "tips on what and where to shop in the US" on various platforms, there are tens of thousands of results. By utilizing hashtags or similar features, social media users do not necessarily need to have a large number of followers to achieve a high-click volume for one specific post. Many with fewer than 100 followers can have several posts that reach over ten thousand readers through tracking hashtags. Being considered as experienced consumers who have the right to speak about their shopping experiences and the value of the products they bought in the US, some tourists move beyond their traditional roles as consumers in destination countries and become cultural intermediaries who, in many cases, unwittingly provide advertisements for products and services.

Posts from the chosen social media platforms demonstrate that many Chinese international tourists who have shopped in the US gave future travelers and potential customers advice regarding what brands to buy and not to buy, where to shop, and what the latest products and services to try out while traveling to the US. Several people mentioned purchasing newly released cosmetic products that are not yet available in China during their trip to the US:

If you ever go to Sephora, you should pick up this eyeshadow palette from Urban Decay. This product is from their latest cosmetic line, but is not yet available in mainland China. If enough people buy it and post about it, the Chinese supplier will probably consider introducing it to Chinese customers.

In this particular video post, the informant encouraged future Chinese tourists to purchase one spe- cific eyeshadow palette from a brand in the hope of setting a trend and potentially signaling to Chinese suppliers to bring this product to mainland China. In other words, the influential power of social media is used to promote new products and lifestyles on behalf of large brands. Further, Chinese tourists continuously shared their reviews of various outlets, stores, restaurants, coffee shops; their shopping experiences in luxury stores; and their perspectives on customer services. In one post analyzed, one person complained about the barista's attitude in a well-known coffee shop and strongly discouraged future tourists from visiting that specific shop:

When I stepped into Blue Bottle for a cup of coffee, I had high expectations. However, after I ordered my coffee and waited there for over five minutes, I did not notice anyone making it. I had to remind the barista again of my order. They did not apologize or anything, one guy just proceeded with my order slowly and reluctantly. The customer service was just ridiculous. If you ever travel to New York, do not go to that coffee shop.

By sharing her experience extensively online, this particular tourist became a credible source for future consumers. Therefore, Chinese international tourists who post their shopping experiences online, either encouraging or discouraging future customers from coming to specific shops in the US, indirectly act as middlemen between future customers and brands. As well as taking on the role of Internet key opinion leader, many eventually become resellers themselves. On numerous social media platforms, many Chinese international tourists publicly offer to purchase items in the US for interested persons, so they can purchase it for them with a small price markup. By taking advantage of the large price differences mentioned in the shopping motives sec- 
tion, these tourist resellers turn their journey to the US into a win-win situation for their customers in China and themselves.

Figure 3. A Chinese tourist holds up a pair of Adidas sneakers to show it to her online audiences

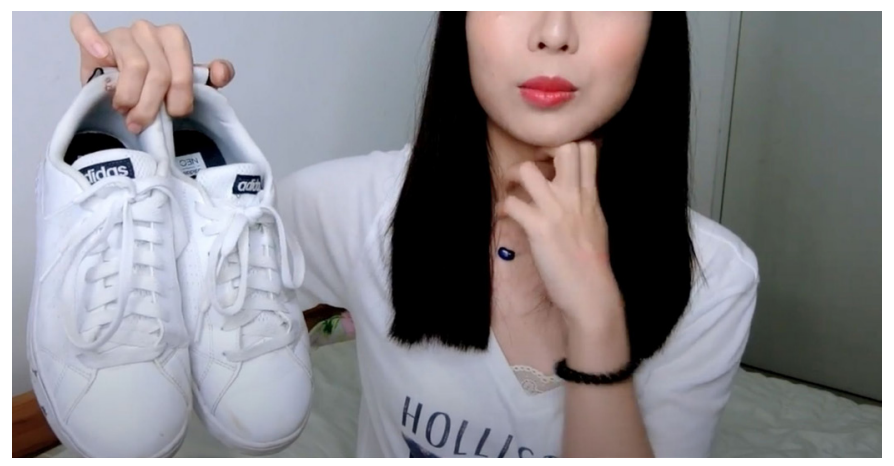

Source: Platform Bilibili.

The phenomenon of tourists taking on the role of resellers that connect retailers in the US and customers in China is particularly apparent on the social media platform Red. On Red, there are two resell models-the resellers will ask potential customers to submit their requests, or they will recommend what they think is popular in the US. The following are two examples to demonstrate these two models:

Hi guys, I will be traveling to the US during the summer. If you need anything, please just message me and let me know. If you are not familiar with what you want to buy in the US or US brands, my recommendation is that you can start with athletic products. Products from Nike and Adidas usually have really large price differences and are all worth checking out.

I want to recommend an indie brand that few people know in China, and it is called Réalisation Par. It is an American brand, and its dresses accentuate your body curve perfectly. I wore it once when I traveled to Thailand, and it was so flattering. I can help to purchase their dresses when I travel to the US. I cannot do a large order since I'm not really a professional reseller, just a tourist. I still need suitcase space for myself lol. Just message me and let me know.

As seen in the above examples, people extend their roles from tourists to resellers during or after their trip. This extended role builds a bridge between Chinese customers and US retailers; meanwhile, their tastes and recommendations mediate between the two cultures and set trends. Resellers' posts are pervasive on social media sites throughout the year, but tend to peak during summer and around national holidays. Many social media users who are not able to travel to the US also share their experiences finding "customized buyers." One person shared her experiences finding various Chinese tourists around the Chinese National Day holiday period to purchase her engagement ring. She said:

It's easy to find tourists as your buyers around national holidays because there are so many of them! I asked multiple people to find me a Tiffany engagement ring in different regions in the US so that I was able to compare the prices. Although you are not able to travel with them, you can find the products you love and have them buy them for you simply by browsing social media apps.

While reselling and setting trends brought profits and a new identity to some tourists during their travel, it can sometimes be accompanied by complaints and dissatisfaction from domestic consumers back in China. In one case of "tourists as resellers and trendsetters," I have seen instances where the reselling tourists had to apologize or 
even end this service after being accused of overpricing or selling counterfeit goods. In this case, the audiences' feedback and reactions have further influenced tourists' presentation of self online. Through maximizing the impact of social media, Chinese international tourists act beyond their role as tourists and become culture intermediaries between potential consumers back in China and businesses in the US. Different features embedded in social media platforms allow their posts to reach a broader audience online, thus further enabling them to present themselves and construct their identities in unconventional ways.

\section{Chinese International Tourists as Good and Loyal Chinese Patriots}

While traveling in a foreign country, tourists' national identity becomes more pronounced compared to when they are in their country of origin. In the case of Chinese tourists in the US, it is likely for them to be recognized collectively as "Chinese." Many feel obligated to not lose face and to convey a positive national image of Chinese people when they travel abroad. Shopping, as one of the most important tourist activities, can move beyond a means of personal pleasure and be used as a way to express political standpoints and construct national identities.

For some people, there is a strong relationship between consuming behaviors and personal beliefs in politics, morals, and justice. After analyzing the social media posts from Chinese tourists, it was observed that many take the chance of sharing their travel purchases online as an opportunity to form identities beyond tourists and consumers. By sharing what to buy and what not to buy, tourists can present themselves as good and loyal Chinese patri- ots. By endorsing certain brands and condemning others, a message of patriotism and nationalism can be sent.

When Chinese tourists share their product reviews and shopping experiences online, whether or not a certain brand supports Tibetan independence is one of the most frequently asked questions. In Chinese Pinyin, "Tibet Independence" translates as $Z a n g D u$, and people who post about this issue online use its abbreviation ZD. People on various social media sites try to identify and share information about US brands that support Tibetan independence based on information such as whether the particular brands' representatives have met with the Dalai Lama or not. By doing so, they intend to persuade their readers and followers to boycott these brands in support of the Chinese Communist Party and Chinese national sovereignty. For example, one person posted a video on Weibo to share what she bought in the US, and in the comments section, a viewer pointed out that one brand she purchased from supports ZD and Tibetan independence, and "as a small influencer, you should boycott brands like that." In her defense, she posted and pinned her response to the top of her profile:

I was in "buy, buy, buy" mode every day and did not notice the large "bomb" I had stepped on. I just came back home and read your comments; the fact that the brand Anastasia Beverly Hills supports ZD is something that I did not know before now. I will not recommend this brand anymore. There's a lot of substitute products out there, so you do not have to purchase an eyeshadow palette from this specific brand.

\footnotetext{
${ }^{6}$ The official romanization system for Standard Chinese in mainland China.
} 
As we can see from this post, it is crucial for any Chinese person who shares their haul video or product review to have a firm stand on issues regarding national sovereignty. For the audience, the national sovereignty of China is non-negotiable and needs to be addressed almost immediately. On Red, they typically use hashtags like \#supportsZD and \#ZDbrand to warn future customers about specific brands that support Tibetan independence. By expressing political opinions while sharing what they bought during the trip, they demonstrate that they are not only tourists and consumers but also Chinese patriots and loyal Chinese citizens. Of the posts analyzed, there were no posts publicly supporting Tibetan independence. Such opposing views are either directly censored altogether by the Chinese government or kept private by the individuals themselves.

Hong Kong, Macau, and Taiwan are also frequently mentioned in national sovereignty issues. In 2019, luxury brands such as Versace, Givenchy, and Coach mistakenly identified Hong Kong, Macau, and Taiwan as independent countries on their websites and items of clothing. This incident caused considerable online backlash and calls to boycott these brands in China. While noting that Chinese people enjoyed purchasing Coach handbags at outlet stores, one particular tourist suggested that "at this special moment, we as Chinese citizens should do our part to protect China's territorial sovereignty and stop purchasing from this brand." As said by one tourist on Red, "you are first a Chinese citizen, then a consumer," hoping to discourage tourists who come to the US from purchasing specific brands perceived as disloyal. Overall, many tourists consider their purchasing power as a form of leverage to force large Western businesses to comply with the so-called "Chinese laws and regulations" unconditionally.
China is a key market for luxury brands; thus, many of them quickly expressed regret and contrition for their mistake after the eruption of a backlash from Chinese social media users.

Other than issues regarding the unification of China, Chinese tourists also frequently post to remind future customers not to purchase from brands that have posted racist content about Chinese or Asian people in general. Many initiate online social movements to urge people to use social media as a tool to express their disappointment publicly on brands' online accounts. In the example below, one Chinese tourist posted about Tarte, a Western cosmetics brand, after it referred pejoratively to Chinese people as "Ching Chong" on their Instagram page. The tourist explained the racial slur to people who may not be familiar with it and encouraged future tourists to boycott this brand when traveling to the US:

This brand posted a meme picture on their Instagram page a couple of months ago, and in the caption section, they used the word "Ching Chong." If you are not familiar with this word, it is a racial slur targeting Asian people. It's similar to the N-word for black people. It's extremely offensive. I know that many of you want to purchase their cosmetic products because they are cheap and of good quality, but I encourage you to reconsider it. If you travel to the US, there are so many other options.

Besides this, many videos and posts talked about boycotting US celebrities and their endorsed products because they had posted racist content on their social media in the past. Multiple people on Red discussed one US celebrity's video post and notified future tourists not to purchase products that she endorsed: 
Gigi Hadid posted a video in which she squinted her eyes intentionally to mock Asian people. Let's try not to purchase her products when we travel to the US, and maybe get her banned in China forever, as well.

Trust me, you don't really need this pair of jeans she [Gigi Hadid] wears. If you don't respect Chinese people, then you don't take money from us. This [boycotting her brand] is something that all Chinese who are abroad should do together.

The Chinese government has banned almost all forms of social movements and political protests in mainland China, except for collective actions that propagate nationalism and patriotism. As can be seen in the examples above, when Chinese tourists share their shopping experiences on different social media platforms, they are expected to present themselves as good and loyal Chinese citizens by boycotting certain brands that violate the territorial integrity of China or demean Chinese people in general. In this sense, Chinese international tourists are not just tourists but defenders of Chinese national interests.

\section{Enacting and Balancing Competing Identities Online}

As discussed in the previous section, social media platforms and the much-extended groups of virtual audiences allow Chinese international tourists to present various multi-faceted identities online. Compared to constructing and presenting themselves solely as tourists, they are capable of becoming cultural intermediaries, global consumers, trendsetters, and Chinese patriots. Although most people analyzed in this study do not embody all types of identities simultaneously, in many cases, Chinese tourists who talk about their consumption experiences online need to be strategic and exercise caution when presenting competing identities so that the expansive pool of audiences will not feel offended.

Overall, there is a clear tension between presenting the global and the national self when tourists share their consumption experiences online. This phenomenon is particularly real when tourists wish to present global identities as cultural intermediaries, trendsetters, and national identity Chinese patriots simultaneously. For instance, in one post on Red, one tourist who visited the US discussed how young people in China could consider copying American fashion styles. In the comment section, a commenter confronted her and said, "What is the problem with the ways Chinese people dress? American culture should not be prioritized over our own." In this example, presenting a global self as a trendsetter can sometimes conflict with presenting as a loyal Chinese patriot. While introducing Western fashion trends to the local audiences in mainland China, Chinese tourists often face judgment from their fellow countrymen for seemingly prioritizing Western culture over their own. This requires them to carefully balance these competing identities using a variety of tactics.

Among all the tourists examined for this study, the strategic balancing of global and national identities happened more often among people who already had a particularly large fan base. Based on the data analysis, if a Chinese tourist is already an "Internet influencer"7 who can potentially monetize the content they post, balancing the roles of being a Chi-

\footnotetext{
7 "Influencers in social media are people who have built a reputation for their knowledge and expertise on a specific topic." See: https://influencermarketinghub.com/what-is-an-influencer/. Retrieved February 29, 2020.
} 
nese patriot, a fashion influencer, and a profitable content provider becomes even more crucial. As one subscriber noted under a Chinese blogger's video, "if you are already making money out of your Chinese fans, you had better watch your words and not comment bad things about China." Noticeably, several Internet influencers who had a fan base between 5,000 to 100,000 sometimes use various forms of disclaimers in their videos or posts to balance their multiple roles. For example, at the beginning of a video in which one Chinese tourist/influencer shared her shopping haul in the US, she first announced that,

I am not rich at all, and my family is just middle-class. I am not making this video to brag about what I purchased or expressing how good American products are. I understand that many of our local brands in China have already surpassed a lot of foreign brands, both in quality and style.

By having this type of disclaimer either at the beginning of the post or as a later response, many sought to portray to their audiences that purchasing Western brands should not disqualify them from being considered loyal Chinese patriots.

Although not the research subject of this paper, similar criticism can also be found in the comment sections of Chinese bloggers who reside in the US. For instance, one Chinese blogger named Vicky Soupsss was forced by her audiences to stop posting for several months because she posted a picture with an American YouTuber named Serpent_Za, who once criticized China publicly on his channel. There are also cases where Chinese bloggers were even forced to quit career after collaborating with another person who, according to their fans, supported the independence of Taiwan or the protesters in Hong
Kong. Overall, Chinese international tourists, especially those with an established fan base, are expected to strategically balance their global and national identities so that their audiences can be satisfied with their self-presentations and monetize the content they post online.

\section{Discussion and Conclusion}

As discussed by many previous scholars (McCracken 1990; Thornton 1995; Maffesoli 1996; Cohen 2003; Noble 2004; Reimer and Leslie 2004; Sassatelli 2007; Maguire and Matthews 2012; Martens and Casey 2016), consumption has long moved beyond meeting basic living needs and has become a way for people to construct their identity, discover meanings in their lives, and mark themselves apart from other groups. As a result of globalization, international tourism has become a significant contributor to consumption, and international tourists, as analyzed in this paper, see shopping as one of the primary motivations for traveling. In turn, shopping becomes a way for them to construct their identity beyond simply being a tourist and consumer. Furthermore, with the use of social media during and after their trips, tourists are expected to balance multiple identities carefully when they project themselves online-on the one hand, they present themselves as global consumers who are shrewd and savvy; whilst on the other hand, they still need to preserve and even emphasize their national identity and show how loyal and patriotic they are as Chinese citizens.

In this paper, to analyze Chinese international tourists' presentations of self on different virtual platforms, data were collected from four popular social media sites where tourists share their shopping experiences and tips. Chinese international tourists 
present themselves first as good community members by discussing how they select different souvenirs and gifts for friends, family, and colleagues, thus maintaining healthy relationships with people around them. Further, they discuss their shopping strategies and share tips about what and where to shop when they travel abroad to the US. By doing so, they present themselves as affluent and smart global consumers. Social media platforms and the utilization of hashtags or labels allow them to ascend to trendsetters by informing their Chinese audiences what is popular in the US, with some tourist resellers serving the role of cultural intermediaries between potential customers back in China and brands in the US. Finally, posting about how they use their purchasing power as political leverage enables many Chinese tourists to present themselves as good and loyal Chinese citizens.

This present paper contributes to the study of international tourism, consumption, and the construction of digital self in multiple ways: first of all, this particular study complements Goffman's theoretical framework by extending the field of research into virtual settings and focusing on the combined effect among international travel, consumption, and the use of social media on the construction and presentation of people's digital self. Moreover, this research provides readers with much-lacking qualitative insights into the exploration of tourists' consumption behavior and its connection to Chinese nationalism in the digital age. As demonstrated by the data, many tourists were forced to make statements regarding the products they had purchased if it was perceived that a brand had disrespected China's sovereignty. Any posts that did not sufficiently promote patriotism or display positive images of China were subjected to severe attack and criticism online. Some tourists and social media users also face the dilemma that requires them to strategically manage the tension between their competing global and national identities. Overall, the paper discussed the complexities and the liberating, yet constraining aspects of presenting one's self in virtual settings-people can present themselves in myriad diverse ways online, and all that while their presentations are constantly being monitored and policed by more and more audiences outside their immediate life circle. This sometimes requires them to creatively conduct self-presentation so that their competing identities can be strategically balanced.

Another larger irony that emerged from the data was tourists' obsession with the American way of living along with the preservation of their national identity as Chinese patriots. Their fascination, yet distanced attitude toward the US should be situated and understood within a broader social context. On the one hand, their presentation of such conflicting identities should be situated within the context of China's economic ascendence. As mentioned above, China is not only the largest tourist-generating country in the world but Chinese tourists also bring big revenues to the destination countries. Being able to travel and shop abroad is a great testament to their financial strength and purchasing power, and sharing their shopping experiences online helps them further confirm their identity as wealthy global consumers. Along with the economic boom was the growth of Chinese national identity. Historically, China has gone through a significant national identity crisis since the mid- $19^{\text {th }}$ century largely due to the Opium Wars, the Sino-Japanese War, and a series of foreign invasions (Gries 2004). In the $19^{\text {th }}$ century, China was portrayed as the "sick man of East Asia," and as Scott notes in his 2008 work, contemporary Chinese national identity still grows out of China being the victim of the hostile West. There- 
fore, Chinese tourists visit the culturally dominating country with great curiosity, yet bearing a mild hostility toward the US-based on coverage and propaganda in the domestic media. They want to embrace the American culture and lifestyle, yet also carry a strong sense of national pride, especially toward the "hostile West."

One limitation of the paper is that the majority of the posts analyzed came from female social media users in their 20s to 40s. Some possible explanations for the unbalanced gender ratio include: first, a primary source of data for this paper, the platform Red, has a predominantly female audience of approximately 88 percent; simultaneously, 83 percent of their users are Millennials born between 1982 and 2000. Secondly, women today still share the responsibilities as purchasers both for themselves and their entire families. Being a strategic and smart consumer is still a common expectation for women in the context of China. Another weakness is that this study only focused on consumption experiences that had been shared online, which represents a rather small portion of global consumption activities. Like most qualitative studies that do not aim to generalize their findings, another limitation of this present paper is that the findings may not be able to generalize to other groups of population such as US international tourists in China or domestic Chinese tourists.

Another shortcoming of this study is that since the data were videos, pictures, or texts posted online, it was difficult to capture how audiences' feedback and reactions have further influenced the performers' self-presentations. In other words, interactions that happened back and forth in cyberspace were hard to be fully presented and understood in the same way as physical interactions. Only in some rare scenarios, such as when a post was highly controversial, will the blogger give a new round of feedback addressing their previous performances. Additionally, given that all posts analyzed were in Simplified Chinese and Mandarin, how people from other parts of the world react to Chinese tourists' presentations of self in various virtual settings was not examined. However, through collecting and analyzing various forms of data from Chinese social media sites, I hope that this paper has helped, in some small way, to deepen people's impressions of Chinese tourists in the age of globalization. This study has provided some insights into how globalization operates at a micro-level and can serve as a starting point to unpack the various issues and interactions people face in the digital age. The case of China is unique because of the Internet surveillance imposed by the government-Chinese people need to be cautious about what they post online; otherwise, they will not only take the risk of having their posts deleted and their accounts canceled, but they may also be subject to legal action for what they say. As a result of living under such censorship for long, many Chinese netizens have also internalized this set of standards for online speech and use it to examine the speech and posts of others. However, the case of China, on some level, might also shed light on exploring the virtual self-presentation of people in other parts of the world. In the age of social media when performers' presentations of self constantly orient towards a virtual group of the audience outside their life circles, they need to manage and balance their identities more creatively compared to traditional face-to-face interactions to seek the audiences' approval.

Conclusively, future studies on international tourism and consumption should continue to cultivate social media sites as an essential source of data and 
further explore the consumption, interaction, and presentations of self that take place in virtual settings. Recently, the tourism industry has been massively affected by the spread of coronavirus. It is

\section{References}

Albayrak, Tahir, Meltem Caber, and Nesli Çömen. 2016. “Tourist Shopping: The Relationships among Shopping Attributes, Shopping Value, and Behavioral Intention." Tourism Management Perspectives 18:98-106.

Arlt, Wolfgang Georg. 2013. "The Second Wave of Chinese Outbound Tourism." Tourism Planning E Development 10(2):126-133.

Arnould, Eric J. and Craig J. Thompson. 2005. “Consumer Culture Theory (CCT): Twenty Years of Research." Journal of Consumer Research 31(4):868-882.

Baillargeon, Lisa and Patrice Gélinas. 2011. "Single- and Multi-Ideology Marketing in the Province of Quebec in the Early Twentieth Century." Journal of Macromarketing 31(1):32-43.

Bao, Jigang, Xin Jin, and David Weaver. 2019. "Profiling the Elite Middle-Age Chinese Outbound Travellers: A 3rd Wave?" Current Issues in Tourism 22(5):561-574.

Belk, Russell W. 1988. "Possessions and the Extended Self." Journal of Consumer Research 15(2):139-168.

Bourdieu, Pierre. 1984. Distinction: A Social Critique of the Judgment of Taste. London: Routledge.

Butler, Richard. 1991. "West Edmonton Mall as A Tourist Attraction." The Canadian Geographer/Le Géographe Canadien 35(3):287-295.

Carlson, Allen. 2009. "A Flawed Perspective: The Limitations Inherent Within the Study of Chinese Nationalism." Nations and Nationalism 15(1):20-35.

Chan, Winnie W. Y. et al. 2014. “Behavioral Determinants That Drive Luxury Goods Consumption: A Study within the Tourist Context." Research Journal of Textile \& Apparel 18(2):84-95. also important for future scholars to pay close attention to how COVID-19 and the worldwide pandemic shape tourists' identities and the stigmas Chinese/ Asian-looking tourists might face afterward.

Charmaz, Kathy. 2014. Constructing Grounded Theory. $2^{\text {nd }}$ ed. Los Angeles, London, New Delhi, Singapore, Washington: Sage.

Chen, X. 1997. Shopping Experiences of Tourists. Master's Thesis, Utah State University, Logan, Utah.

Cheng, Mingming and Anthony Ipkin Wong. 2014. "Tourism and Chinese Popular Nationalism." Journal of Tourism and Cultural Change 12(4):307-319.

Cheng, Mingming and Carmel Foley. 2018. “Understanding the Distinctiveness of Chinese Post-80s Tourists Through an Exploration of Their Formative Experiences." Current Issues in Tourism 21(11):1312-1328.

Cohen, Lizabeth. 2003. A Consumers' Republic: The Politics of Mass Consumption in Postwar America. New York: Alfred A. Knopf.

Cooley, Charles H. 1983. Human Nature and the Social Order. New York: Routledge.

Correia, Antonia, Metin Kozak, and Seongseop Kim. 2018. "Luxury Shopping Orientations of Mainland Chinese Tourists in Hong Kong: Their Shopping Destination." Tourism Economics 24(1):92-108.

Côté, James. 2006. “Identity Studies: How Close Are We to Developing A Social Science of Identity? An Appraisal of the Field." Identity 6(1):3-25.

Daunton, Martin and Matthew Hilton, eds. 2001. The Politics of Consumption: Material Culture and Citizenship in Europe and America. Oxford: Berg.

Featherstone, Mike. 1991. Consumer Culture and Postmodernism. London: Sage Publications. 
Foster, Robert J. 2011. "The Uses of Use Value: Marketing, Value Creation, and the Exigencies of Consumption Work." Pp. 4257 in Inside Marketing: Practices, Ideologies, Devices, edited by D. Zwick and J. Cayla. Oxford: Oxford Scholarship.

Gabriel, Yiannis and Tim Lang. 1995. The Unmanageable Consumer: Contemporary Consumption and Its Fragmentation. London: Sage.

Gao, Zhihong. 2012. “Chinese Grassroots Nationalism and Its Impact on Foreign Brands." Journal of Macromarketing 32(2):181-192.

Gecas, Viktor. 1982. "The Self-Concept." Annual Review of Sociology 8(1):1-33.

Gerth, Karl. 2008. "Consumption and Politics in Twentieth-Century China." Pp. 34-50 in Citizenship and Consumption, edited by K. Soper and F. Trentmann. London: Palgrave Macmillan.

Glaser, Barney G. and Anselm L. Strauss. 1967. Discovery of Grounded Theory: Strategies for Qualitative Research. Chicago: Aldine Publishing.

Goffman, Erving. 1959. The Presentation of Self in Everyday Life. New York: Penguin Books.

Gottschalk, Simon. 2010. "The Presentation of Avatars in Second Life: Self and Interaction in Social Virtual Spaces." Symbolic Interaction 33(4):501-525.

Gries, Peter Hays. 2004. China's New Nationalism: Pride, Politics, and Diplomacy. Berkeley, Los Angeles, London: University of California Press.

Heung, Vincent C. S. and Hailin Qu. 1998. “Tourism Shopping and Its Contributions to Hong Kong." Tourism Management 19(4):383-386.

Hooper, Beverley. 2000. "Globalisation and Resistance in PostMao China: The Case of Foreign Consumer Products." Asian Studies Review 24(4):439-470.

Huang, Qunfang and Yuqi Lu. 2017. “Generational Perspective on Consumer Behavior: China's Potential Outbound Tourist Market." Tourism Management Perspectives 24:7-15.

Ictech, Brad. 2019. "Smartphones and Face-to-Face Interaction: Digital Cross-Talk During Encounters in Everyday Life." Symbolic Interaction 42(1):27-45.

Jansen-Verbeke, Myriam. 1987. “Women, Shopping, and Leisure." Leisure Studies 6(1):71-86.
Jansen-Verbeke, Myriam. 1990. “Leisure + Shopping = Tourism Product Mix." Proceedings of the ISA Congress, Madrid.

Jin, Haipeng, Gianna Moscardo, and Laurie Murphy. 2017. "Making Sense of Tourist Shopping Research: A Critical Review." Tourism Management 62:120-134.

Kendall, Lori. 1998. "Meaning and Identity in 'Cyberspace': The Performance of Gender, Class, and Race Online." Symbolic Interaction 21(2):129-153.

Keown, Charles F. 1989. “A Model of Tourists' Propensity to Buy: The Case of Japanese Visitors to Hawaii." Journal of Travel Research 27(3):31-34.

Kincade, Doris and Ginger A. Woodard. 2001. "Shopping for Souvenir Clothing." Pacific Tourism Review 5(3/4):159-165.

Kroger, Jane. 1989. Identity in Adolescence: The Balance Between Self and Other. New York: Routledge.

Lash, Scott and Celia Lury. 2007. Global Culture Industry: The Mediation of Things. Malden, MA: Polity.

Law, Christopher M. 1993. Urban Tourism: Attracting Visitors to Large Cities. London: Mansell.

Lehto, Xinran Y. et al. 2004. “Tourist Shopping Preferences and Expenditure Behaviours: The Case of the Taiwanese Outbound Market." Journal of Vacation Marketing 10(4):320-332.

Li, Hongmei. 2008. "Branding Chinese Products: Between Nationalism and Transnationalism." International Journal of Communication 2:1125-1163.

Li, Hongmei. 2009. "Marketing Japanese Products in the Context of Chinese Nationalism." Critical Studies in Media Communication 26(5):435-456.

Lin, Yueh-Hsiu and Kelly Q. R. Lin. 2006. “Assessing Mainland Chinese Visitors' Satisfaction with Shopping in Taiwan." Asia Pacific Journal of Tourism Research 11(3):247-268.

Liu, Shuk-Ching, Tsan-ming Choi, and Wing Tak Lee. 2008. “Tourists' Satisfaction Levels and Shopping Preferences Under the Solo Travel Policy in Hong Kong." Journal of Fashion Marketing and Management 12(3):351-364.

Liu, Tingting and Mimi Li. 2020. "Leisure \& Travel as Class Signifier: Distinction Practices of China's New Rich." Tourism Management Perspectives 33. doi: 10.1016/j.tmp.2019.100627. 
Lu, Jia and Ian Weber. 2009. “Internet Software Piracy in China: A User Analysis of Resistance to Global Software Copyright Enforcement." Journal of International and Intercultural Communication 2(4):298-317.

Maffesoli, Michel. 1996. The Time of the Tribes: The Decline of Individualism in Mass Society. London, Thousand Oaks, New Delhi: Sage.

Maguire, J. Smith and Julian Matthews. 2012. "Are We All Cultural Intermediaries Now? An Introduction to Cultural Intermediaries in Context." European Journal of Cultural Studies 15(5):551-562.

Martens, Lydia and Emma Casey. 2016. Gender and Consumption: Domestic Cultures and the Commercialisation of Everyday Life. London: Routledge.

McCracken, G. David. 1990. Culture and Consumption: New Approaches to the Symbolic Character of Consumer Goods and Activities. Bloomington, Indianapolis: Indiana University Press.

McIntosh, Robert Woodrow, Charles R. Goeldner, and Ritchie J. R. Brent. 1995. Tourism: Principles, Practices, Philosophies. $7^{\text {th }}$ ed. New York: Wiley.

McKercher, Bob et al. 2020. "Travel by Chinese: A Generational Cohort Perspective." Asia Pacific Journal of Tourism Research 25(4):341-354.

Mead, George H. 1934. Mind, Self and Society. Chicago: University of Chicago Press.

Nelson, Laura C. 2000. Measured Excess: Status, Gender, and Consumer Nationalism in South Korea. New York: Columbia University Press.

Noble, Greg. 2004. “Accumulating Being.” International Journal of Cultural Studies 7(2):233-256.

Page, S. J. 1992. "Managing Tourism in A Small Historic City." Town E Country Planning. 61(7/8):208-211.

Parmentier, Guy and Sylvie Rolland. 2009. "Consumers in Virtual Worlds: Identity Building and Consuming Experience in Second Life." Recherche et Applications en Marketing (English Edition) 24(3):43-55.

Patterson, Ashley N. 2018. "YouTube Generated Video Clips as Qualitative Research Data: One Researcher's Reflections on the Process." Qualitative Inquiry 24(10):759-767.

Pecotich, Anthony and Melissa J. Rosenthal. 2001. "Country of Origin, Quality, Brand and Consumer Ethnocentrism." Journal of Global Marketing 15(2):31-60.
Pretes, Michael. 2003. "Tourism and Nationalism." Annals of Tourism Research 30(1):125-142.

Prus, Robert and Lorne Dawson. 1991. "Shop 'til You Drop: Shopping as Recreational and Laborious Activity." Canadian Journal of Sociology 16(2):145-164.

Reimer, Suzanne and Deborah Leslie. 2004. “Identity, Consumption, and the Home." Home Cultures 1(2):187-210.

Reisinger, Yvette and Lindsay W. Turner. 2002. “The Determination of Shopping Satisfaction of Japanese Tourists Visiting Hawaii and the Gold Coast Compared." Journal of Travel Research 41(2):167-176.

Ritzer, George. 2003. “Rethinking Globalization: Glocalization/ Grobalization and Something/Nothing." Sociological Theory 21(3):193-209.

Rojek, Chris. 2011. Pop Music, Pop Culture. Malden, MA: Polity.

Romano, Tricia. 2010. “Look What I Bought (or Got Free).” New York Times, May 06. Retrieved February 14, 2015 (https://www. nytimes.com/2010/05/06/fashion/06skin.html).

Sassatelli, Roberta. 2007. Consumer Culture: History, Theory, Politics. London: Sage.

Schor, Juliet. 2004. Born to Buy: The Commercialized Child and the New Consumer Culture. New York, London, Toronto, Sydney: Simon and Schuster.

Scott, David. 2008. China and the International System, 1840-1949: Power, Presence, and Perceptions in a Century of Humiliation. Albany, NY: State University of New York Press.

Shimp, Terence A. and Subhash Sharma. 1987. "Consumer Ethnocentrism: Construction and Validation of the CETSCALE." Journal of Marketing Research 24(3):280-289.

Smart, Barry. 2010. Consumer Society: Critical Issues and Environmental Consequences. London: Sage.

Stearns, Peter N. 2006. Consumerism in World History: The Global Transformation of Desire. New York: Routledge.

Sthapit, Erose. 2017. "Exploring Tourists' Memorable Food Experiences: A Study of Visitors to Santa's Official Hometown." Anatolia 28(3):404-421.

Strangelove, Michael. 2010. Watching YouTube: Extraordinary Videos by Ordinary People. Toronto: University of Toronto Press. 
Thornton, Sarah. 1995. Club Cultures: Music, Media, and Subcultural Capital. Middletown, CT: Wesleyan University Press.

Tsang, Nelson K. F., Louisa Yee-Sum Lee, and Carrie K. L. Liu. 2014. "Understanding the Shopping Motivation of Mainland Chinese Tourists in Hong Kong." Journal of China Tourism Research 10(3):323-346.

Underhill, Paco. 1999. Why We Buy: The Science of Shopping. New York: Simon and Schuster.

Wang, Jian. 2006. "The Politics of Goods: A Case Study of Consumer Nationalism and Media Discourse in Contemporary China." Asian Journal of Communication 16(2):187-206.
Warde, Alan. 2015. "The Sociology of Consumption: Its Recent Development." Annual Review of Sociology 41:117-134.

Wong, Ipkin Anthony and Yim King Penny Wan. 2013. “A Systematic Approach to Scale Development in Tourist Shopping Satisfaction: Linking Destination Attributes and Shopping Experience." Journal of Travel Research 52(1):29-41.

Wu, Xu. 2006. Chinese Cyber Nationalism: Evolution, Characteristics, and Implications. Lanham, MD: Lexington Books.

Zhao, Shanyang. 2005. "The Digital Self: Through the Looking Glass of Telecopresent Others." Symbolic Interaction 28(3):387405.

\section{Citation}

Ma, Fangheyue. 2021. "'You Are First a Chinese Citizen, Then A Consumer': Presenting and Balancing Identities Online as Chinese International Tourists." Qualitative Sociology Review 17(4):58-81. Retrieved Month, Year (http://www.qualitativesociologyreview.org/ENG/archive_eng.php). DOI: https://doi.org/10.18778/1733-8077.17.4.04 